\title{
Nonlinear Finite Element Simulation of Steel Frames-Composite Steel Shear Wall
}

\author{
Xiaotong PENG ${ }^{1, a}$, Lei XIA ${ }^{1, b}$, Chen $\operatorname{LIN}^{2, c}$, Tingting ZHANG ${ }^{1, d}$ \\ 1School of Civil Engineering and Architecture, University of Jinan, Jinan 250022 , China \\ ${ }^{2}$ School of Architecture and Landscape Design, Shandong University of Art \& Design, Jinan 250014, \\ China

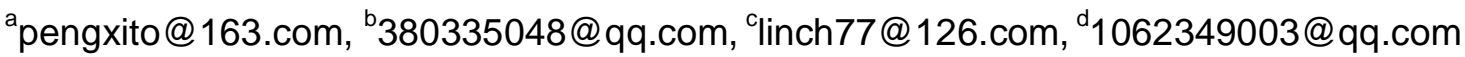

Keywords: Composite steel Shear Wall, Nonlinear Finite Element, Simulation, seismic Behavior.

Abstract. The prefabricated concrete walls are used to cover on both sides of steel shear wall to avoid the buckling of steel plates, which leads to the composite steel shear wall system. In order to carry out the nonlinear FEM analysis on the composite steel shear wall, the procedure of establishing the FEM model was illustrated in details, in which the nonlinear and contact behavior were considered. The computed results were in good match with test data, which indicating the simulation method is feasible. It would accurately reflect the mechanical behavior of the structure by use of surface-to-surface smooth hard contact properties to simulate the contact between the steel plate and concrete cover plates.

\section{Introduction}

The Steel structure is widely used for multi-layer and high-rise building for its good seismic performance. However, it is easy to produce a large lateral displacement under lateral loads for its low stiffness. Therefore, the steel frame is usually adopted in combination with the lateral load resisting members ${ }^{[1][2]}$. The composite steel wall is composed of embedded steel plate and concrete cover plates. The steel framecomposite steel shear wall (SFCW) structure makes up the shortcomings of the regular steel plate shear wall, which is prone to buckling under lateral loads. Concrete covering on both sides of the embedded steel plate, not only improve the buckling strength of the steel plate, but also has the fireproof effects ${ }^{[3][4]}$. The composite shear wall resists most of the seismic loads, which provides the opportunity to use semi-rigid connections.

\section{Test profile}

The test specimen adopted semi-rigid connections, and the detail dimensions and material properties of beams and columns are illustrated in document [5] and Table 1. The loading history is divided into 14 stages (Table 2), and controlled by peak displacement. Out-plane restraints are arranged on both sides of the beam. The fixed connection is realized on the foot of the specimen. 
Table 1. Properties of components

\begin{tabular}{cccc}
\hline $\begin{array}{c}\text { Performance } \\
\text { evaluation }\end{array}$ & $f_{y} /[\mathrm{MPa}]$ & $f_{u} /[\mathrm{MPa}]$ & E/[MPa $]$ \\
\hline Beam web & 304 & 452 & $2.18 \times 10^{5}$ \\
Beam flange & 308 & 473 & $2.18 \times 10^{5}$ \\
Column web & 321 & 475 & $2.18 \times 10^{5}$ \\
Column flange & 301 & 476 & $2.18 \times 10^{5}$ \\
End plate & 347 & 484 & $2.18 \times 10^{5}$ \\
Steel plate & 259 & 400 & $2.18 \times 10^{5}$ \\
$\varphi 6$ Steel & 383 & 479 & $2.18 \times 10^{5}$ \\
\hline
\end{tabular}

Table 2. Loading history

\begin{tabular}{cccccc}
\hline No & $\begin{array}{c}\text { Top } \\
\text { displacement/[mm }]\end{array}$ & $\begin{array}{c}\text { Cycle } \\
\text { index }\end{array}$ & No. & $\begin{array}{c}\text { Top } \\
\text { displacement/[mm }]\end{array}$ & $\begin{array}{c}\text { Cycle } \\
\text { index }\end{array}$ \\
\hline 1 & 2 & 1 & 8 & 36 & 3 \\
2 & 4 & 1 & 9 & 42 & 3 \\
3 & 6 & 1 & 10 & 48 & 3 \\
4 & 12 & 3 & 11 & 54 & 3 \\
5 & 18 & 3 & 12 & 60 & 3 \\
6 & 24 & 3 & 13 & 66 & 2 \\
7 & 30 & 3 & 14 & 72 & 2 \\
\hline
\end{tabular}

\section{ABAQUS finite element analysis}

Material properties. In order to simulate the seismic behavior of SFCW structure under cyclic loading, the kinematic hardening model and nonlinear elastic model are combined to form a complete constitutive relationship. Moreover the Bauchinger effect of steel is also considered.

The concrete constitutive relation adopt the damaged plastic model ${ }^{[6]}$. The tensile and compressive behavior of concrete is calculated based on the Z.H.Guo's curve ${ }^{[7]}$.

Element type. In this paper, the steel frame and the embedded steel plate are modeled using four nodes curved shell elements (S4R). Concrete is simulated by eight nodes hexahedral elements (C3D8R). On purpose of avoiding bending rigid caused by shear locking, the reduced integral element is adopted as well as the enhanced hour glassing to simulate the deformation accurately. Steel is modeled using two joints linear three-dimensional truss elements (T3D2).

Mesh division. In order to save computer time and keep accuracy, it is suitable for each member to specify the appropriate grid size both for the global distribution and for the local self-modification. It is also necessary to arrange nodes at the prepared hole of bolt when dividing the grid.

Interaction and contact problem. The interaction between steel and concrete is simulated by embedded region. A multi point constraint (MPC constraint) is performed at the points of bolt. Moreover, the MPC beam constraint is used to handle the beam-column section of semi-rigid joints, and the rotating spring is arranged at the center of cross section to achieve the rotational stiffness of semi-rigid joints. The contact between the steel plate and the concrete slab is considered as surface-to-surface contact.

Boundary conditions and loads. The fixed end constraint is applied at the bottom of the model. The middle and top beam is constrained by the displacement boundary conditions so as to realize the lateral restraint. Furthermore, the loading is controlled by peak displacement. At the loading points, they are 
assumed to be rigid to avoid the local deformation. Interaction and boundary conditions are shown in Figure $1 \sim 2$.

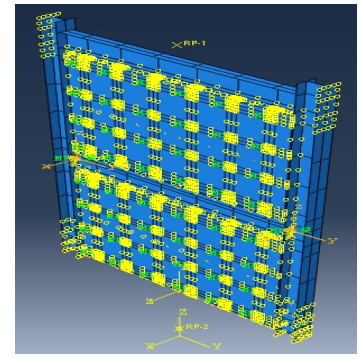

Fig. 1 Interaction

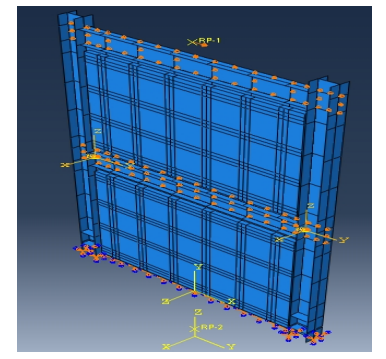

Fig. 2 Boundary conditions

Algorithm. The nonlinear analysis is based on the explicit dynamic algorithm ${ }^{[8][9]}$, the geometric nonlinear switch is on. In order to improve the efficiency and accuracy of calculation, a suitable analysis step length need to be determined. In this paper, the eigenvalue buckling analysis of steel plate should be conducted before monotonic and cyclic loading. Moreover, its first order buckling mode should be added to composite shear wall model as initial imperfection.

\section{Comparison of calculation results and test}

It can be seen from Figure 3 and Figure 4, the calculation results match well with that of test. There is a dense buckling in the center and sparse buckling on the edge of plate. This phenomenon is good reflect the restraint behavior of concrete plates on steel plates.

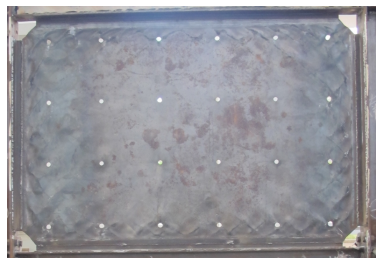

Fig. 3 Deformation

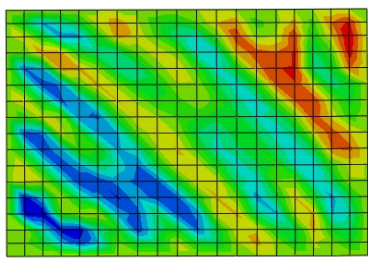

Fig. 4 stress nephogram

Ultimate bearing capacity.It can be seen from Figure 5 6, the ultimate bearing capacity of specimen reached $820 \mathrm{kN}$ at the lateral drift of $60 \mathrm{~mm}$. whereas the calculated model reached the peal value $817 \mathrm{kN}$ at the same drift with minor errors.

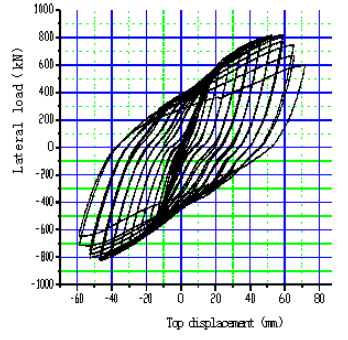

Fig. 5 Hysteretic curve of test

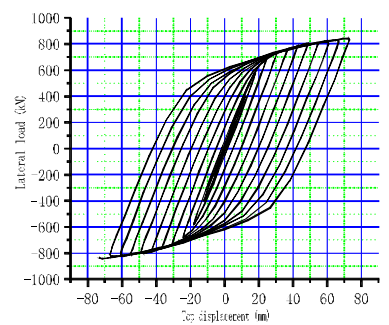

Fig. 6 Hysteretic curve of simulation

Energy dissipation.The calculated hysteretic curve based on FEM can reflect the hysteretic energy dissipation capacity of the structure especially in the elastic phase. In general, this FEM model can be used for the numerical analysis of the SFCW structure. 
Error analysis.Given that the finite element method does not consider the material damage, thus it can't reflect the failure phenomenon. This model is assumed under an ideal condition, which is why the calculative hysteretic curve is much plumper.

\section{Conclusions}

(1) The results of finite element analysis are in good agreements with experiment data, so the simulation method that used in the FEM model is feasible.

(2)Because the factor of material damage has not been considered in the modeling, it fails to reflect the failure behavior of structure. Therefore, further efforts on that should be made in future.

(3)Adopting surface-to-surface contact and smooth hard contact is a practical way to simulate the interaction between concrete cover plates and steel plates.

\section{Acknowledgement}

The work was sponsored by National Natural Science Foundation of China (51078169) and Key Research and Development Program of Shandong Province (2015GSF122003). The writers gratefully acknowledge the support provided.

\section{References}

[1]D.H.Liu, C.R.Yang,X.G.Zhong, Seismic Design Code for High-rise Building, China Architecture\&Building Press,BeiJing,1993.

[2]Y.J.Xu,D.H.Liu,X.G.Zhong,et al, Structural Design Code for Tall Steel Buildings,Shanxi Science and Technology Publishing House, Xi' an, 1998.

[3]A.Astaneh-asl, Seismic behavior and design of composite steel plate shear walls,R,Moraga: Structural Steel Educational Council,2002 .

[4]M.Makino,A.Kawano,Y.Kurobane,etal, An investigation for the design of framed structures with infill walls,C,Istanbul: Proceedings of the Seventh World Conference on Earthquake Engineering, 1980.

[5]Y.Y.Hou,X.T.Peng, Aseismatic Design of A New Type Steel Frame-Composite Steel Plate Shear Wall,Journal of University of Jinan(Sci. andTech. ), 27(2013): 410-413.

[6]Y.Z.Wang,C.G.Fu, ABAQUS Analysis of Structural Engineering and Detailed Examples,China Architecture\&Building Press,BeiJing,2010.

[7]GB50010-2010, Design Code for Concrete Structures[S].

[8]Y.P.Shi,Y.R.Zhou, ABAQUS Finite Element Analysis of Detailed Examples,Mechanical Industry Press,BeiJing ,2006. 